\title{
Multilevel modelling of Demand Responsive Transport (DRT) trips in Greater Manchester based on area-wide socio-economic data
}

\author{
Chao Wang • Mohammed Quddus • Marcus Enoch • \\ Tim Ryley $\cdot$ Lisa Davison
}

Published online: 29 October 2013

(c) The Author(s) 2013. This article is published with open access at Springerlink.com

\begin{abstract}
Providing public transport in areas of low demand has long proved to be a challenge to policy makers and practitioners. With the developing economic, social and environmental trends, there is pressure for alternative solutions to the policy of subsidising conventional bus services. One potential solution is to adopt more flexible routes and/or timetables to better match the required demand. Therefore such 'on demand' or 'Demand Responsive Transport' (DRT) services (known as paratransit in the US) have been adopted in a number of locations. This paper seeks to explore the effects of area-wide factors on the demand of DRT by reporting the results of a statistical analysis of DRT service provision in the metropolitan region of Greater Manchester, the public transport authority of which offers one of the largest and most diverse range of DRT schemes in the UK. Specifically, this paper employs a multilevel modelling approach to investigate the impact of both DRT supply-oriented factors at the service area level and socio-economic factors at the lower super output area (LSOA) level on the average number of trips made by DRT per year. This hierarchical or 'nested' structure was adopted because typically the LSOAs within the same Service Area may share similar characteristics. It is found that the demand for DRT services was higher in areas with low car ownership, low population density, high proportion of white people, and high levels of social deprivation, measured in terms of income, employment, education, housing and services, health and disability, and living environment.
\end{abstract}

C. Wang $(\bowtie)$

Medical Sciences Division, University of Oxford, Oxford OX3 9DU, UK

e-mail: excelwang@gmail.com

M. Quddus · M. Enoch · T. Ryley

Transport Studies Group, School of Civil and Building Engineering, Loughborough University, Loughborough, Leicestershire LE11 3TU, UK

L. Davison

Built Environment Research Institute, School of the Built Environment, University of Ulster, Jordanstown Campus, Shore Road, Newtownabbey, Co. Antrim, Northern Ireland BT37 0QB, UK 
Keywords Demand Responsive Transport (DRT) - Flexible public transport ·

Paratransit · Multilevel statistical modelling · Area-wide socio-economic

factors $\cdot$ System-wide effects

\section{Introduction}

For the purpose of this paper, public transport can be categorised as being Demand Responsive Transport (DRT) if: (1) the service is available to the general public (i.e. it is not restricted to particular groups of user according to age or disability criteria); (2) the service is provided by low capacity road vehicles such as small buses, vans or taxis; (3) the service responds to changes in demand by either altering its route and/or its timetable; and (4) the fare is charged on a per passenger and not a per vehicle basis.

In practice, in more developed economies DRT has emerged as an intermediate mode that can provide public transport access to members of the general public in areas where demand is too low to support conventional forms of bus-based public transport systems. However, despite the apparent increase in the number and scale of such locations, DRT remains a relatively niche tool applied by transport providers, and is often restricted to specialist groups of users like the elderly and/or mobility impaired. One reason for this would seem to be a lack of confidence amongst public transport providers as to the effectiveness of such DRT schemes due largely to the non-mainstream reputation. In particular, there is uncertainty as to the types of areas and user groups or 'market segments' that are most appropriate for DRT (Davison et al. 2012a). This is in spite of a growing recognition of the importance of determining the 'user needs' when planning a new service as noted, for example, in Finn et al. (2004).

However, from a UK perspective this view of DRT may now be about to change, not least because of the global financial crisis which, since 2008, has increased the pressures on public sector funding (including public transport). Consequently, DRT is now being seriously considered by several local authorities (e.g. Northamptonshire, Leicestershire, and Cambridgeshire) as a means of providing people with the opportunity to access key facilities at a lower overall cost than conventional public transport options, albeit at higher per passenger trip costs.

Accordingly this paper seeks to explore the relationship between a range of socioeconomic and service area factors and the demand for DRT by reporting the results of a quantitative analysis of DRT service provision in Greater Manchester, which offers perhaps the largest and most diverse range of DRT schemes in the UK. To achieve this, it has employed a multilevel modelling approach, using data from Great Manchester as a case study. The research presented in this paper will be useful to providers of DRT services in assessing the level of demand in urban areas.

The rest of this paper is organised as follows. First it presents an overview of the existing literature on the factors influencing demand for DRT trips. It then provides contextual information as to the study area, details the multilevel model and the data sources employed. Finally, the results are reported and discussed, before conclusions are drawn and recommendations for future research are offered.

\section{Factors affecting the demand for DRT}

In reviewing the literature, it is useful to consider the factors affecting the demand for DRT firstly in terms of supply-side factors, and secondly of demand-side factors at both the 
individual and the area levels (Lerman et al. 1980), though it should be understood that in practice there is a high degree of interaction between the categories, with operational decisions affecting who uses the system (and how often) and vice versa, for example.

From the supply-side perspective there are a range of factors that influence demand. These include:

- operational factors (for example routeing/timetabling methods, booking methods, vehicle types-Li and Quadrifoglio 2010; Brake et al. 2004; Mageean and Nelson 2003);

- technological issues (relating to location plotting, fare collection and on board communication-Lacometti et al. 2004);

- institutional factors (to do with ownership, operation, regulation, tax, insurance and licencing these services, and how these functions are carried out-Enoch et al. 2004); and

- policy factors (particularly regarding availability of finance and subsidy, the objectives/ motivations behind the scheme, and decisions over eligibility criteria. For example, some DRT schemes are available to everyone, whilst others are restricted only to registered members, and/or to local, elderly, low income or mobility impaired usersCervero 1997; Hine 2004; Davison et al. 2012b).

However, such studies typically have not explicitly quantified the effect of DRT system characteristics on DRT demand and/or are narrowly focused on one or two detailed aspects of the DRT service. For instance, Khattak and Yim (2004) interviewed commuters and non-commuters in the San Francisco Bay Area and found that reliability, cost of service, convenient pick-up and drop-off locations, number of other pick-ups and overall travel time were important (in descending order), and that there was preference for a maximum number of eight people in a vehicle. They also found that respondents were willing to pay significantly more for a DRT over a fixed route service. Meanwhile recent (as yet unpublished) work by the authors of this paper, drew on a simple regression analysis of data from a national survey of UK DRT providers to demonstrate that better used schemes provide more seats and vehicles, and are more likely to use booking and reservation software and buses instead of taxis. Specifically, it found that every additional seat provided by a DRT service generates an extra 165 trips per year (i.e. a $1 \%$ rise in seats leads to an increase of ridership of $0.79 \%$ ceteris paribus), and that annual ridership increases by 2363 trips for every extra vehicle provided (or that a $1 \%$ increase in vehicle numbers leads to a $1.01 \%$ increase in patronage).

Considering demand-side factors at the individual level, Rosenbloom and Fielding (1998) studied the OmniLink DRT service in Prince William County, Virginia, USA which was set up in 1995 as the major public transport offering for a (rapidly growing) rural community, and reported that $61 \%$ of users were female, $79 \%$ aged less than 45 and $64 \%$ earned less than $\$ 25,000$ a year. Results from the dial-a-ride transit (DART) scheme in Winnipeg, Manitoba, which was set up to serve people living in suburban areas with connections to fixed route bus services, found that $53 \%$ of users were female, $29 \%$ were aged under 18 while only $2 \%$ were aged 65 or older (Koffman 2004).

On the other hand, Laws (2009) reported that the majority of users of the Wiltshire Wigglybus in the rural district of Pewsey, UK were school children and retired people, with passengers using the service for shopping (33\%), education (10\%), and commuting (29\%) trips, whilst in an even more rural area of Calne in the same County, retired and disadvantaged users predominated, with a few commuters using the buses at peak time to get to work. Similarly in another scheme that was developed to meet social policy 
objectives around improving people's accessibility to services, Nelson and Phonphitakchai (2012) suggested that in the metropolitan area of Tyne and Wear in the UK over half of the users of the service were female and retired, and that (as a result) there was a preponderance of very local trips that do not involve a transfer. Moreover, a third of respondents required the door-to-door element of the service. Interestingly, the schemes described above were all developed to meet the accessibility needs of the communities served, and were all largely driven by local government agencies.

Mageean and Nelson (2003) also found that females are the dominant users of the DRT services in most of the cases they examined from across Europe, which again tended to be set up by public authorities to improve or sustain citizen mobility. Interestingly though, it found that average ages varied from less than 15 years in Finland up to 77 years in Gothenburg (a statistic which reflects its purpose as a service for the elderly and disabled), and noted that these age distributions were reflected in the composition of the users. Thus, two thirds of users in Belgium were retired, house persons and students; in Florence four fifths of users were unemployed or students (due to eligibility criteria); and in Campi and Porta Romana $84 \%$ of users were students and workers.

There are also efforts in quantifying the effects of socio-economic factors on DRT demand. For example, Nguyen-Hoang and Yeung (2010) developed a DRT demand model at the US national level and found that an increased proportion of disabled and elderly people increased the unlinked passenger trips, and that the proportion of poor households was negatively associated with the demand for unlinked passenger trips. Strangely, this seems not to be fully consistent with the findings by SG Associates Inc. et al. (1995), which developed a workbook for estimating demand for DRT services in rural areas based on case studies and reported that DRT users tended to be poorer, a perhaps more intuitive finding. From the studies above, it can be seen that most DRT services are provided in areas with a low population density (though there are exceptions to this), and are targeted at the mobility impaired, the poorest, the youngest and oldest members of society, and women. This is probably to be expected, given the strong public policy ethos, particularly with the focus on improving accessibility behind the creation of these schemes that emerge. Fitzgerald et al. (2000) employed a Poisson model to examine the effect of various individual level attributes, such as age and whether a person requires a mobility aid, on the frequency of DRT trips. They found that increases in age and some disabling conditions reduced trips but having a sight problem increased trips. Finally, by using a time-series model, Bearse et al. (2004) found that women took about $30 \%$ more trips per month than men and that nursing home residents took fewer trips than community residents.

In terms of area characteristics, early work by Nutley (1988) reported that DRT in urban areas in the US mainly targeted the problems of "low-density suburbs", for the purpose of "savings in private car running costs, and relief from driving stress". However, similar effects were not observed in the UK at this time, as presumably conventional public transport was deemed to be adequate. SG Associates Inc. et al. (1995) then differentiated three potential target markets: the elderly, mobility limited, and those on low incomes, categories subsequently reaffirmed in Spielberg and Pratt (2004), which noted that the typical DRT rider in rural areas and communities is likely to be poor, elderly, or disabled. Koffman (2004) drew on a survey of DRT schemes across North America and found that the most common DRT schemes provided the primary public transport service in "limited hard to serve areas", though others operated primary services in large (e.g. rural) areas, or else offered services at times of low demand.

Taking a UK perspective, Davison et al. (2012b) drew on (mostly UK) interviews and focus groups with key DRT stakeholders, to identify that opportunities for developing the 
DRT product included focusing on commuting and business travel trips. Laws et al. (2009) reported the results of a survey of DRT providers across England and Wales and noted that the vast majority of DRT scheme objectives related to delivering 'social' goals (129 compared with 40 for environmental, economic and geographical combined), indicating that DRT was being used to serve groups that were disadvantaged in some way. And in a follow up exercise, Davison et al. (2012a) found that DRT was often perceived as offering the most cost effective way of ensuring that rural communities without a conventional bus service were still able to provide access to services, though not if considered on a per passenger trip basis. Enoch et al. (2006) provided a qualitative evaluation of DRT in the rural county of Wiltshire, but offered no quantitative measures as to what (or where) the most suitable market niches may be. It is interesting to note that Balcombe et al. (2004) reported that "as yet, few operational results are available [relating to DRT]" (p. 99), and did not report any numerical results on how demand factors and DRT use were relatedthis, in a comprehensive meta-analysis of factors affecting public transport use.

In summary, the existing supply-side studies have been narrowly focused on specific attributes of the DRT experience, whilst the demand-side studies have tended to consider the needs of disabled and elderly people. In addition, as shown, the majority of the quantitative studies were based on individual level data, whilst relatively few examined DRT demand using spatial area-wide data. As a result, 'system wide effects', including socio-economic variables such as deprivation and population density, have largely been ignored and yet these may well exert a significant effect on the performance of DRT schemes. Hence these are the research gaps that this study aimed to help address.

\section{Research context}

In order to identify and investigate the factors affecting the demand for DRT, this paper used data from Greater Manchester as a case study.

Greater Manchester is a conurbation in the North West of England, comprising Manchester City Council and nine other metropolitan borough councils with an estimated total population of 2.7 million in mid-2011 (ONS 2013). Transport for Greater Manchester (TfGM-previously known as Greater Manchester Passenger Transport Executive, GMPTE) co-ordinates transport provision for the metropolitan area. Local Transport Plans are co-ordinated at the regional level by the Passenger Transport Executive (i.e. TfGM), outlining plans and investment across each of the authorities. Public transport in Greater Manchester comprises a heavy rail network, the Metrolink light rail network, and a bus network as well as the demand responsive and community transport services. DRT, branded "Local Link", is provided where there is insufficient demand for conventional bus provision to provide links to essential services and the wider transport network. The Local Link service is supplemented by "Shopping Link" services providing more targeted access for shoppers. During the period of the third Local Transport Plan (i.e. from April 2011), a 5-year transport plan that all authorities in England and Wales must develop, there are proposals to integrate these services with social services, passenger transport and Ring and Ride, Greater Manchester's dial-a-ride provision (GMCA and TfGM 2011). In total there are 37 DRT schemes, corresponding to 37 service areas (SA), operating across Greater Manchester plus a dial-a-ride service, which is available to people who find it difficult to use conventional public transport. DRT trips are typically made within the pre-defined SAs, although there are exceptions where passengers are allowed to be picked up and/or dropped off outside the SAs. Of these, three are 'Shopping Links' and the remaining 34 are 
Local Links; the majority of which are targeted at the general public, providing for a wide range of journey purposes. Further details on the operational context of DRT in the UK can be found in Davison et al. (2012a).

\section{The multilevel model}

This section describes the statistical method employed in this study, which aimed to explore the relationship between a range of socio-economic and service area factors and the demand for DRT in Greater Manchester (GM). Accordingly, the dependent variable in the statistical model is the average number of DRT trip origins per year per LSOA, ${ }^{1}$ whilst the independent variables included a range of area-wide socio-economic and service level factors, more details of which will be provided in the section on data.

A standard linear regression model was tested as a starting point. However, since the DRT services in the study area were operated in several different service areas ${ }^{2}$ (SAs), it was soon recognised that a multilevel model would be more appropriate so as to reflect the likelihood that the trips from the LSOAs within the same service area are correlated. In other words, it assumes that clusters of LSOAs are 'nested' under a $\mathrm{SA}^{3}$ as illustrated in Fig. 1.

From this, it is clear that this model is two-level: LSOA-level trip generation is level 1; LSOAs are nested in several SAs which in turn form level 2. As described above in the Research Context section, there are 37 DRT schemes (and service areas) in Greater Manchester, each with distinctive operational characteristics. Hence there is an assumption that LSOAs within the same SAs may share similar characteristics, which can be taken into account by the multilevel modelling approach used in this study.

In representing this, the multilevel model adopted can be expressed as follows (Laird and Ware 1982):

$$
\mathbf{y}=\beta_{0}+\mathbf{X} \boldsymbol{\beta}+\mathbf{u}_{0}+\mathbf{Z u}+\boldsymbol{\varepsilon}
$$

where $\beta_{0}+\mathbf{X} \boldsymbol{\beta}$ is the fixed part and $\mathbf{u}_{0}+\mathbf{Z u}+\boldsymbol{\varepsilon}$ is the random part of the model. $\mathbf{y}$ represents a vector of responses; $\beta_{0}$ is the fixed effects intercept; $\mathbf{u}_{0}$ represents the random intercepts which is normally distributed with mean zero; $\mathbf{X}$ is a covariate matrix for the fixed effects coefficient $\boldsymbol{\beta} ; \mathbf{Z}$ is a covariate matrix for the random effects $\mathbf{u}$; and $\boldsymbol{\varepsilon}$ represents a vector of errors, which is assumed to be multivariate normal.

In this model, LSOA-level trips within the same SA can be correlated as a result of a shared random intercept $\left(\mathbf{u}_{0}\right)$, or through a shared random slope (u), or both. Specifically, if the smaller area LSOA is denoted as level 1, and the larger area SA as level 2, one can specify random effects at service area (SA) level $\left(\mathbf{u}_{0 i}+\mathbf{Z} \mathbf{u}_{i}\right.$, where $i$ denotes each SA). In this way, service area specific characteristics, such as their hours of operation and other

\footnotetext{
${ }^{1}$ A LSOA is a lower level census tract, and in England there are 32,482 LSOAs with an average population of 1,500 in each in LSOA.

2 The DRT service areas used are the same as those defined and operated by TfGM.

3 Another source of correlation is spatial autocorrelation-in other words, "everything is related to everything else, but near things are more related than distant things" (Tobler 1970). However, it is not straightforward to define the neighbouring structure for modelling such autocorrelation as the areas used in this study are scattered, and the size of these areas varies greatly. Therefore neither a contiguity (i.e. shared border) nor a distance based neighbouring structure was applied here. Instead, a model with an additional conditional autoregressive (CAR) term was tested using an inverse-distance spatial-weighting matrix to model the spatial autocorrelation, and from this it was determined that spatial effect is very marginal and does not affect the original multilevel model significantly.
} 


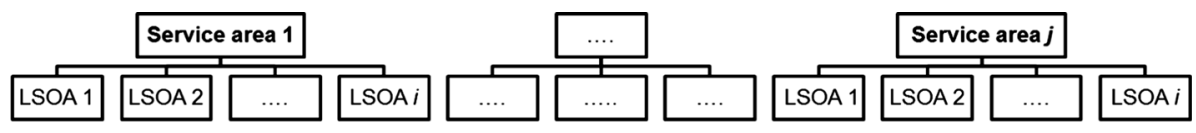

Fig. 1 Multilevel data structure

policies and restrictions, can be controlled for in estimating the number of DRT trips by LSOA.

The fixed portion of Eq. (1) is equivalent to the standard linear regression model estimated using the ordinary least squares (OLS) method. Since the model contains both fixed and random effects, this model is also sometimes referred to as a mixed-effects model. The random effect could happen in intercept $\left(\mathbf{u}_{0}\right)$ only, which forms a random intercept model; and the random effect could also happen in the coefficient (u), which forms a random slope model. The intra-class correlation could be used to describe the portion of variance that exists between high level groups compared to the total variance in the outcome (Heck and Thomas 2009). In the case of this study, intra-class correlation is the ratio of service area level variance to the total variance in the outcome. The multilevel model can be estimated using maximum likelihood method.

\section{Data description and variable selection}

Out of the 37 DRT schemes operational in the Greater Manchester area, Trapeze booking software was used as a management tool for 16 of them, including 15 Local Links and one Shopping Link. These were the schemes for which data were provided by TfGM and subsequently modelled. The data included details of DRT trips, such as date and time of the trip, trip distance, postcodes of the trip origin and destination, the gender of the client who booked the DRT trip, and trip purpose. Unfortunately however, only one supply-side factor-hours of operation-was made available, which is a limitation of the data. In total, some 240,392 DRT trips were made during the period from the beginning of September 2009 until the end of January 2011. Most schemes operated within a given area and provided access to core educational, health, leisure and transport opportunities outside the area. Some exceptions only served major trip generators, either within an area (e.g. Heywood), or outside the area (e.g. to Manchester airport). DRT trips could be booked online or over the phone and booked at least one hour before the time that the customer wanted to travel. Booking was available from 8 am to $8 \mathrm{pm}$ with the exception of the 'Airport Link' service to the airport where booking was available $24 \mathrm{~h}$ per day. A flat fare system was in place across each of the DRT schemes. ${ }^{4}$

Individual trips were mapped and overlaid onto LSOA boundaries in a GIS package. Figure 2 shows the spatial distribution of DRT non-averaged trip generation origins by LSOA from the beginning of September 2009 to the end of January 2011. Interestingly, it is worth noting that nearly $99 \%$ of the study areas were classified as "urban" (ONS 2004). The average area of a LSOA in this study is around $0.64 \mathrm{~km}^{2}$ with the standard deviation of $1.1 \mathrm{~km}^{2}$.

In terms of trip purpose, the highest proportion of trips was for leisure (33\%), which was followed by employment-related trips (29\%), and shopping (17\%). A full list of trip purposes and their percentage of total trips is presented in Table 1. It is worth noting that,

\footnotetext{
${ }^{4}$ Other details of the DRT services including the operation areas are available at http://www.tfgm.com/ buses/local_link/Pages/default.aspx.
} 

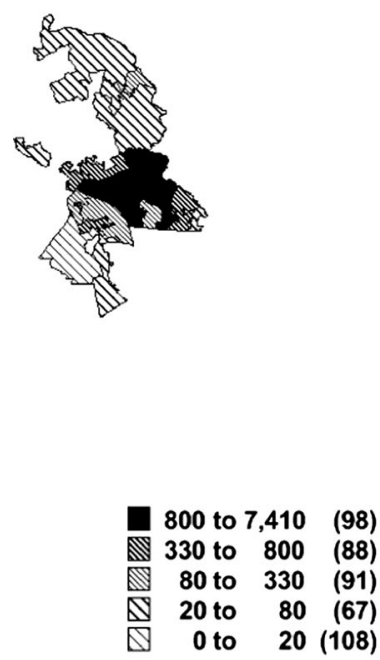

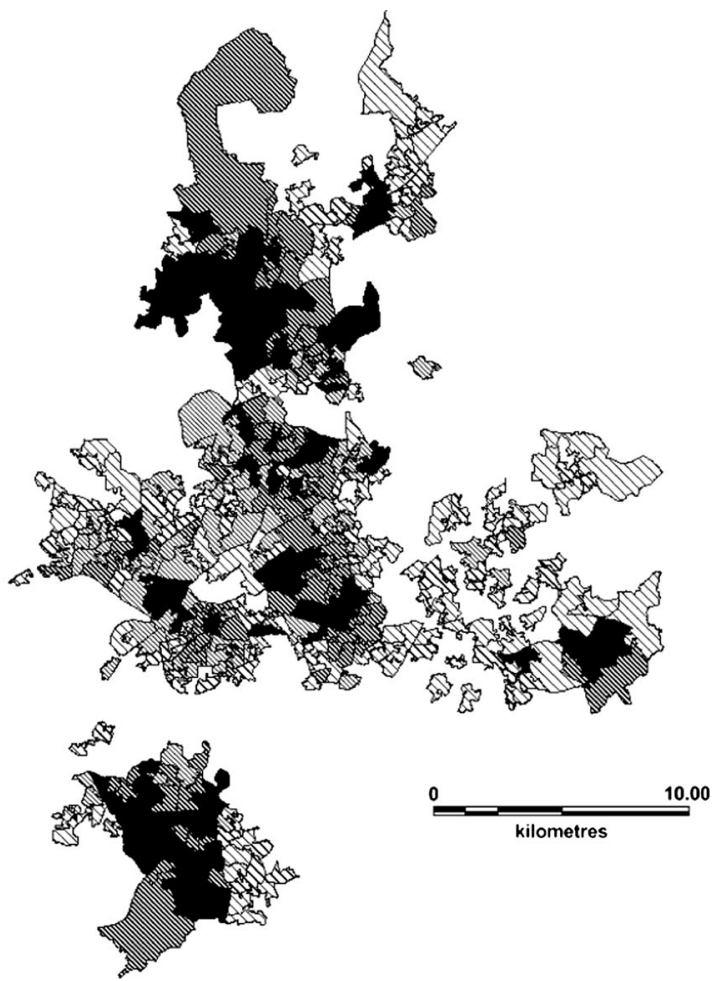

Fig. 2 The spatial distribution of DRT trip origins by LSOA in Greater Manchester (September 2009January 2011)

as expected, the trip purposes were different across service areas. For instance, in the service area of Heywood, employment purpose DRT trips comprised $67 \%$ of all DRT trips probably as a result of the focus on employment areas, whereas in Hindley, $61 \%$ of trips were made for leisure. It is clear that, as stated in the methodology section, the characteristics of service areas differed greatly. Therefore it was essential to employ a multilevel modelling technique to take into account the service area level specific characteristics.

Since this paper analysed DRT trip generation at an area-wide level (i.e. LSOA level), individual trips were aggregated to the LSOA level, so that the count of trips per LSOA could be obtained.

In addition to trip data, LSOA level data on socio-economic factors were also collected so that the impact of these factors on trip generation could be explored. These were primarily obtained from the UK Census 2001, and included data on population, employment, gender, ethnicity, age cohort, number of people working from home, the transport mode people used to work, number of people who are permanently sick or disabled, and number of cars per household. It should be noted that the census data is almost 10 years older than the DRT trip data, and given that socio-economic patterns may have changed considerably during this period, this may have biased the modelling results. This is one limitation of this paper.

From the data on the transport mode people used to travel to work, it was straightforward to calculate the proportion of public transport to all transport modes, which may be 
Table 1 DRT trip purposes

\begin{tabular}{lcc}
\hline Trip purpose & Frequency & Percentage \\
\hline Daycare & 4,985 & 2.09 \\
Dentist & 240 & 0.10 \\
Doctors & 6,716 & 2.82 \\
Education & 10,319 & 4.33 \\
Employment & 67,093 & 29.08 \\
Hospital visit & 10,401 & 4.36 \\
Leisure & 78,866 & 33.08 \\
Personal & 128 & 0.05 \\
Respite & 132 & 0.06 \\
Religious & 10,021 & 4.20 \\
Shopping & 39,521 & 16.58 \\
Visiting & 7,744 & 3.25 \\
\hline
\end{tabular}

used as a proxy for the level of public transport accessibility. In addition to this data (which was derived from the Census 2001), other relevant data on public transport accessibility was obtained from TfGM, including number of bus stops (with frequency of at least one bus per week) in a LSOA and percentage of addresses within $400 \mathrm{~m}$ of a bus stop.

Deprivation data were obtained from the English Indices of Deprivation (ID) 2007, which was published by the Department for Communities and Local Government (DCLG 2008). The ID 2007 is the UK Government's official measure of multiple deprivations at LSOA level and it measures deprivation through seven main domains, namely income, employment, health and disability, education, housing and services, crime, and living environment. These scores were then weighted and combined to create the Index of Multiple Deprivation (IMD), giving an overall indication of deprivation in a LSOA. The IMD 2007 was provided along with the ID 2007 from the same source. Simply, the higher a deprivation score, the more deprived the area. The details of each ID score are described as follows (DCLG 2008):

- Income deprivation: This domain captures the proportion of the population experiencing income deprivation in an area. This has been achieved by reference to the percentage of the population reliant on various benefits.

- Employment deprivation: This domain measures employment deprivation conceptualised as involuntary exclusion of the working-age population from the world of work, indicated by data such as recipients of Jobseekers Allowance and Incapacity Benefit.

- Health deprivation and disability: This domain identifies areas with relatively high rates of people who die prematurely or whose quality of life is impaired by poor health or who are disabled across the whole population. This domain measures morbidity, disability and premature mortality but not aspects of behaviour or environment that may be predictive of forthcoming health deprivation.

- Education deprivation: The Education, Skills and Training Deprivation domain measures deprivation in educational attainment, skills and training for children, young people and the working age population in a local area. The domain considers indicators such as the proportion of young people not staying on in school or non-advanced education above the age of 16 and the proportion of working age adults with no or low qualifications.

- Housing and Services deprivation: this domain measures barriers to housing and key local services. The indicators include 'geographical barriers' (e.g. road distance to a 
surgery, supermarket, primary school) and 'wider barriers' which includes issues relating to access to housing such as affordability.

- Crime: this domain measures the rate of recorded crime for four major volume crime types-burglary, theft, criminal damage and violence-representing the risk of personal and material victimisation at a small area level.

- Living environment: this domain identifies deprivation in the quality of the local environment both within and beyond the home. The domain consists of two subdomains which focus, respectively, on deprivation in the 'indoors' (e.g. houses in poor condition and/or without central heating) and the 'outdoors' living environment (e.g. air quality and road traffic accidents involving injury to pedestrians and cyclists).

In the data analysis, it was found that some variables were highly correlated with other variables, and as such these variables were not included in the same model to avoid the problem of collinearity. For example, household car ownership was found to be highly correlated with IMD and various ID scores (except housing and living environment scores), therefore a car ownership model was developed separately from the IMD model. Unsurprisingly, various ID scores were correlated to each other (see Table 2), which meant that the ID scores could not be included in the model simultaneously. Another issue in the data was that there were some cases of overlap between LSOAs and DRT service areas-in other words, some LSOAs fell into two different service areas-and since the multilevel modelling technique used in this paper explicitly defined the hierarchical structure of the data, some LSOAs which overlapped with service areas were excluded from the model too. As a result of this, a LSOA could only belong to one SA in the model. In total, 127 out of 453 LSOAs were excluded resulting in 15 groups (service areas, where 'Clifton and Moorside' was excluded). However, this appears to have had little impact on the modelling results, as the tests showed that the standard linear model using the OLS method produced very similar results using either full or sub-samples of the data.

Summary statistics of the variables used in the models are presented in Table 3. There were a total number of 326 observations (i.e. data points) for each of the LSOA level variables (these are reported in Table 3). The proportions of male, white and aged 65 or over each referred to the proportion of a given group of people to the whole population in a LSOA. The proportion of people working from home, on the other hand, referred to the proportion of people working from home compared to all people aged 16-74 in employment. These variables were included to examine whether certain types or groups of people were more likely to take DRT trips. Note here that some LSOAs had a very low annual number of trips with the minimum value being 1.41 trips per year, although the high standard deviation figure for this variable (434.85) indicates that the demand for DRT in different areas varied greatly. Another possible reason for the low mean value of annual number of trips might be that there are cases where only a part of a LSOA was covered by the DRT service. However, this could not be tested due firstly to the SA boundary data not being available, and secondly because exceptions are sometimes made in allowing people to be picked up from points outside of the SA, this should be noted as a limitation of the study.

The relationships between demand for DRT (trips per year) and various passengers related socio-economic factors at the LSOA level are presented in Fig. 3. It can be seen that it is difficult to conclude from the figure whether there is a positive or negative relationship between DRT demand and these socio-economic factors. This may be due to the fact that all factors affecting DRT demand need to be taken into account when developing a relationship. Therefore a series of statistical models were required to understand how various factors affect DRT demand. 
Table 2 Correlation coefficients between various deprivation scores

\begin{tabular}{llllllll}
\hline & IMD & Crime & Education & Employment & $\begin{array}{l}\text { Health } \\
\text { and } \\
\text { disability }\end{array}$ & $\begin{array}{l}\text { Housing } \\
\text { and } \\
\text { services }\end{array}$ & Income Living \\
environment
\end{tabular}

\section{Modelling results}

A series of multilevel models were developed to explore the effects of various socioeconomic factors on the demand for DRT in Greater Manchester, where LSOA was considered to be level 1 and service area to be level 2 .

A random intercept model was initially used as the base model, and a range of random slope models were estimated to see whether any explanatory variables were randomly distributed over the service areas. The coefficients of various explanatory variables were then tested as random parameters ${ }^{5}$ using a step-wise approach (i.e. one random coefficient at a time), though in the event it was found that many of the random coefficients tested were statistically insignificant. In addition, the results of random-parameters models were found to be similar to random intercept models in terms of the set of statistically significant variables and the values of their coefficients; whilst the differences in log likelihood values of the various models were less than 2.5 (meaning that the statistical fits were also similar). Therefore this paper only presents the results from the random intercept multilevel models.

Next, the dependent variable — annual average number of trips per LSOA—was transformed into a logarithmic scale to avoid the potential problem of a negative number of trips being predicted. Data transformations for other variables were also considered and tested, such as using a logarithmic form of IMD score, so as to improve model fit and inference.

A model with car ownership variable was developed and compared with a model including deprivation variables. Since the various ID scores are generally highly correlated to each other, they were not included in the model simultaneously. Instead, the model using the overall deprivation score-IMD score-was developed as a starting point and then other component ID scores were added to the model replacing IMD score, thus giving an insight into how different forms of deprivation affect DRT demand. The modelling results using car ownership and IMD score are presented in Table 4; models using other ID variables are presented in Table 5.

In a multilevel model, the inter-class correlation coefficient (ICC) reveals the percentage of 'between group' (between DRT service areas) variability in observed variance

\footnotetext{
${ }^{5}$ By assuming a normal distribution.
} 


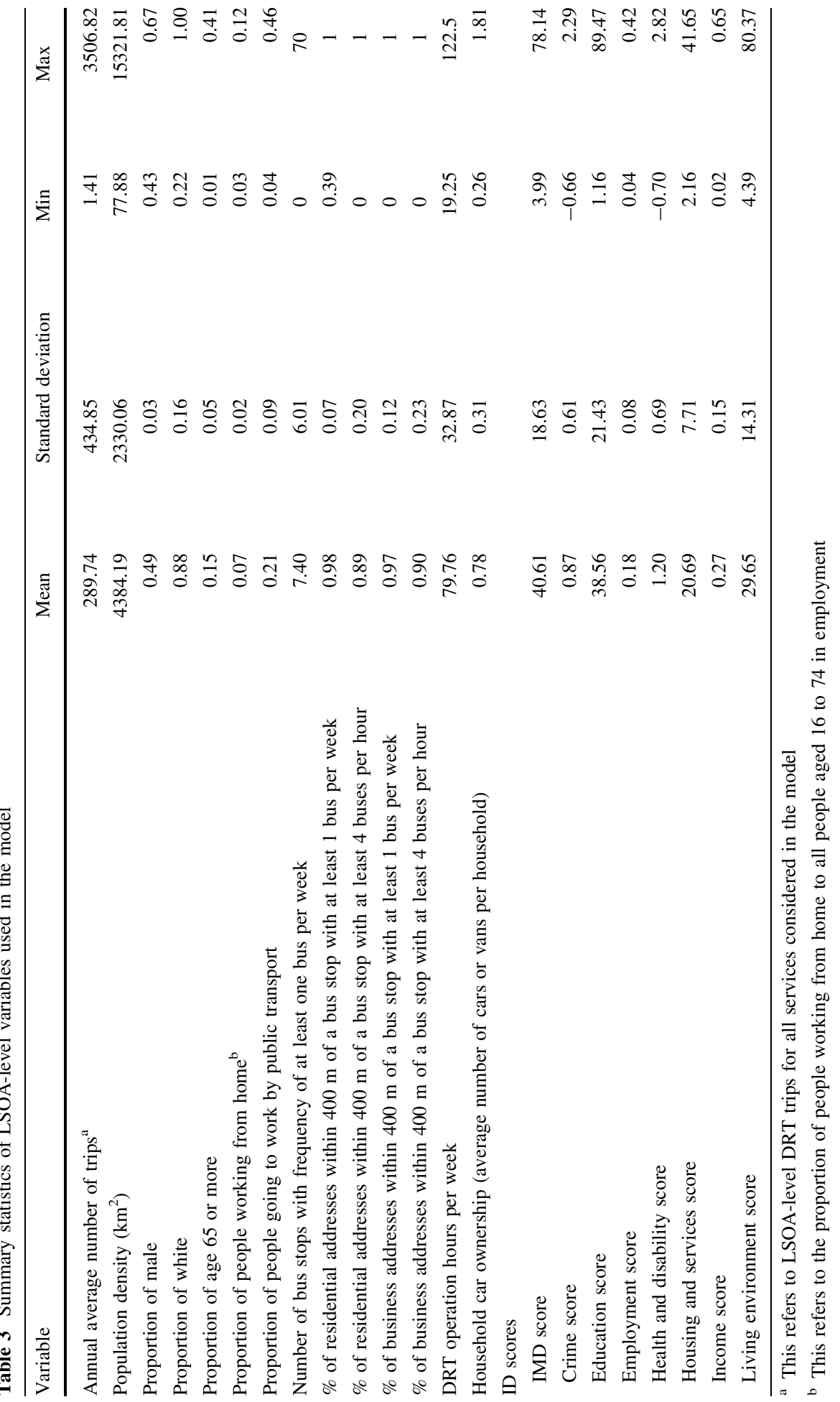



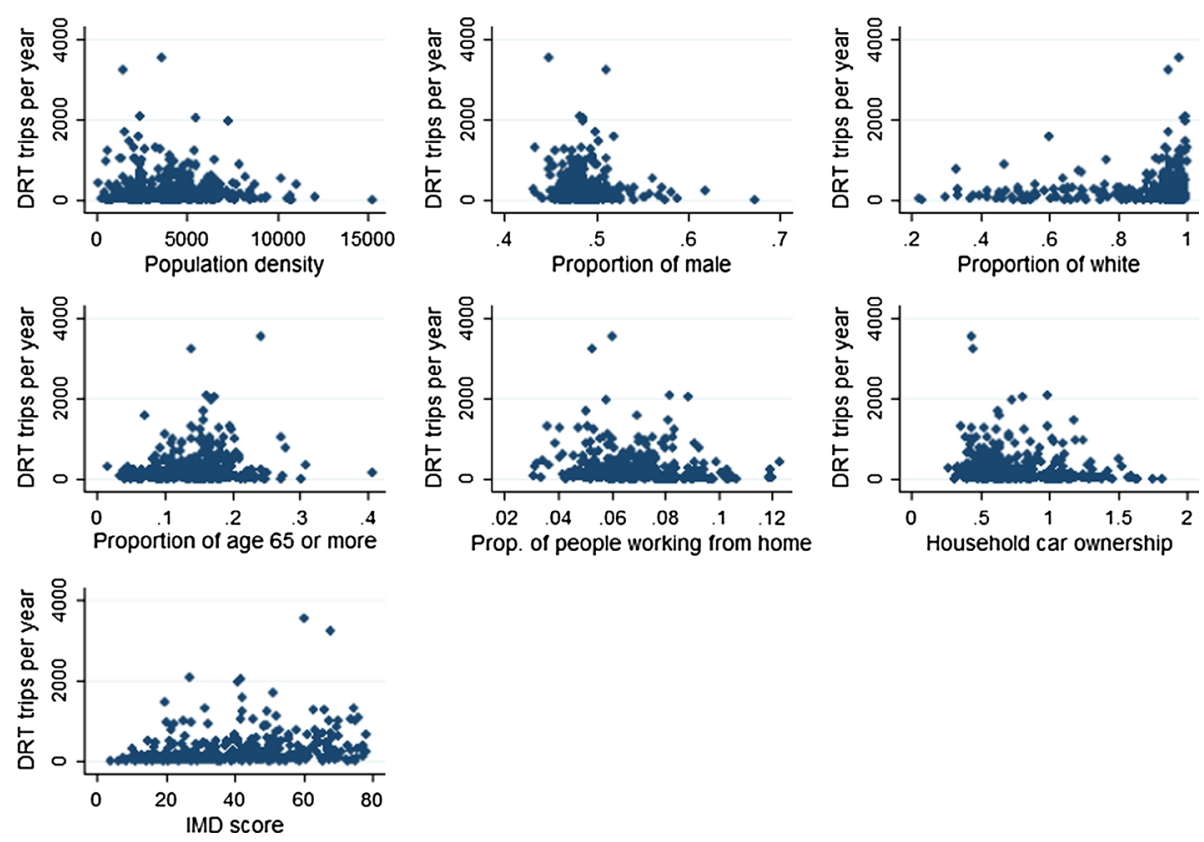

Fig. 3 Relationships between demand for DRT (trips per year) and various passengers related socioeconomic factors

(i.e. DRT trips). As shown in Table 4 the ICC ranges from 0.202 to 0.222 , which means that around $20 \%$ of the variation in DRT trips stems from between-group (i.e. differences in SA characteristics) differences. This in turn suggests that the use of the multilevel modelling approach is appropriate and necessary for analysing DRT trips in Greater Manchester. The likelihood ratio index for the IMD model is higher than the car ownership model, suggesting that the IMD model provides a slightly better fit to the data.

Since there is a loglinear relationship between DRT trips and area-wide attributes, the following formula was employed to estimate the percentage change in DRT trips for a $\delta$ unit change in an area-wide independent variable $x_{k}$ (if this independent variable entered in the models as a linear form), holding all other variables constant (Long and Freese 2006):

$$
100 \times\left\{\exp \left(\beta_{k} \delta\right)-1\right\}
$$

In which $\beta_{k}$ is the estimated coefficient (as shown in Table 4) associated with the areawide attribute $x_{k}$.

From Table 4 it can also be seen that both the coefficients of the car ownership and $I M D$ variables were statistically significant, indicating that areas with a higher level of car ownership or lower level of overall deprivation generate fewer DRT trips. If the number of cars per household in a LSOA increases by 1 unit, the number of DRT trips would decrease by $81.5 \%$ in that area, holding all other variables constant. Similarly a $1 \%$ increase in the IMD score would result in a $1 \%$ increase in DRT trips. As noted earlier though, IMD score is an overall measurement of deprivation which combines seven domain indices and so to better understand the effects of deprivation on DRT demand, individual domain indices were modelled in turn to see if a better fit could be obtained by replacing IMD score with a 


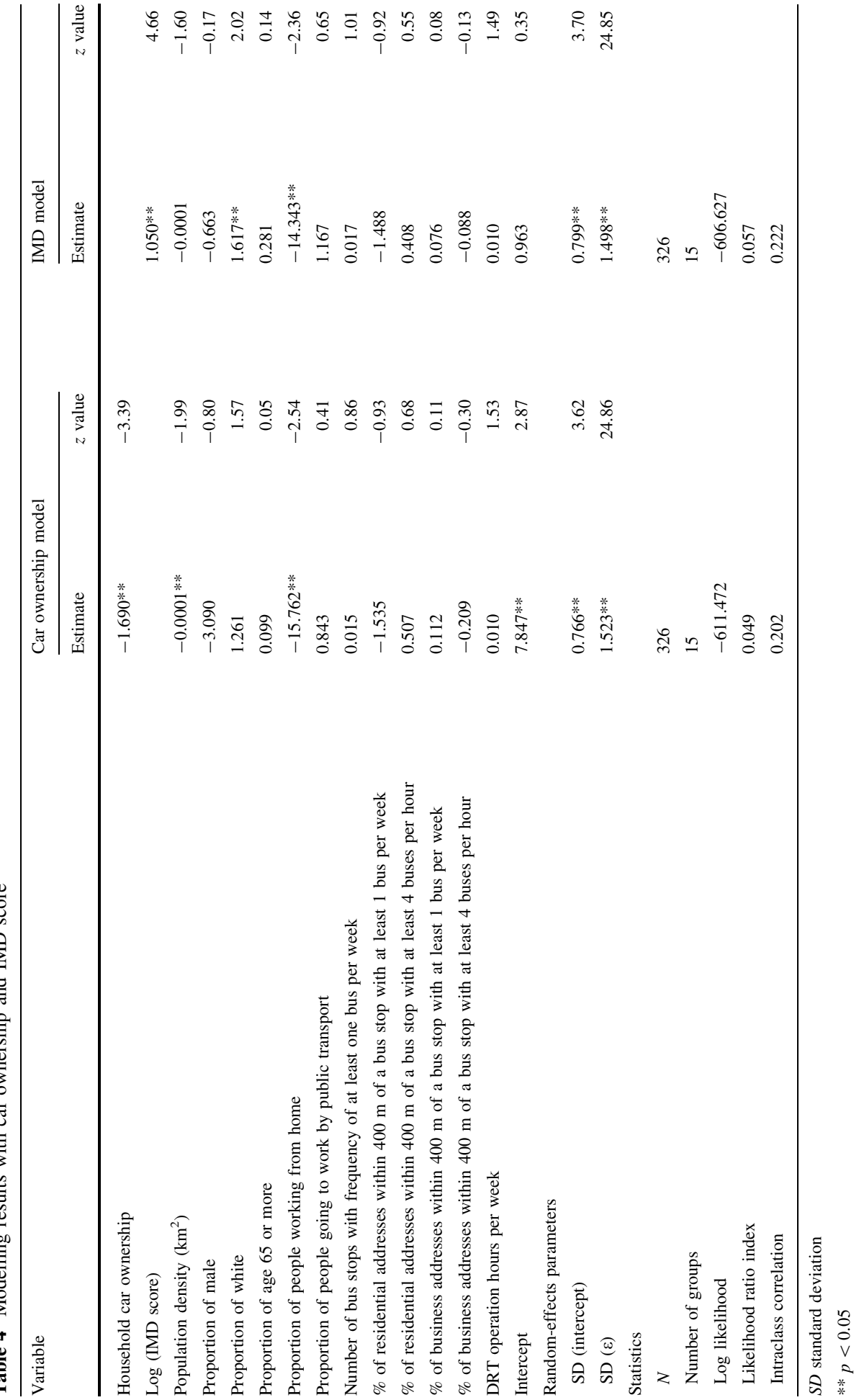




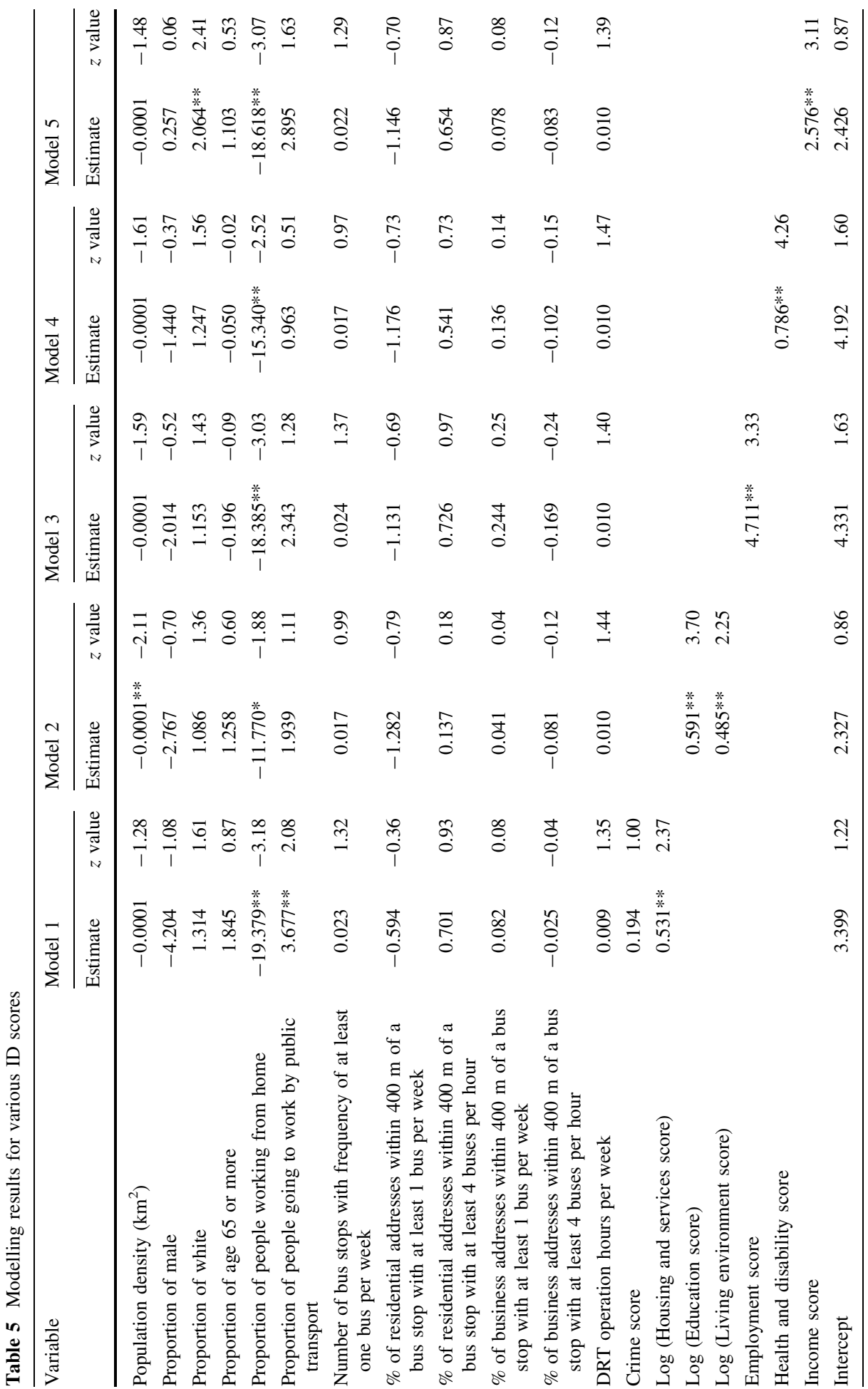




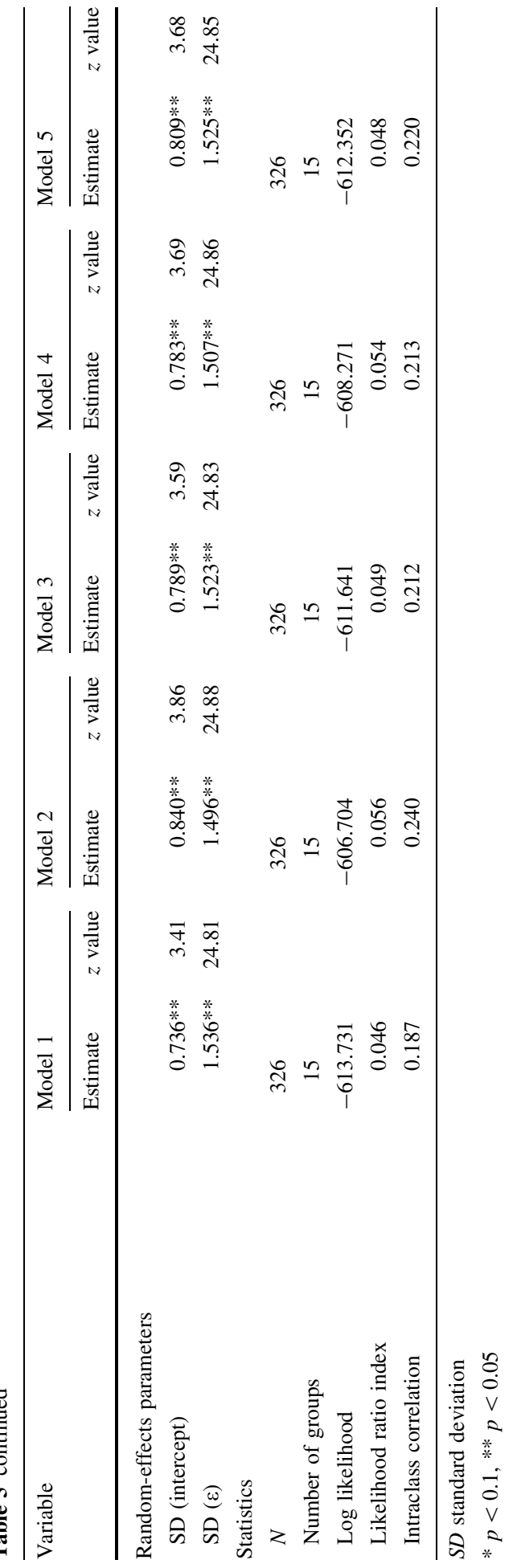


combination of two or more ID scores. In all, once allowances had been made for multicollinearity, five such models were estimated, as discussed below.

The coefficient of population density was negative and statistically significant at $95 \%$ confidence level in the car ownership model, suggesting that people in areas with lower population density tend to make more DRT trips. Specifically, for a 100 unit increase in population density in a LSOA (i.e. 100 more people per $\mathrm{km}^{2}$ ), DRT trips would decrease by $1 \%$ in the area, holding all other variables constant. This may be because regular bus services in these areas were limited (e.g. in terms of bus frequency), probably due to the lower population density which generated a higher demand for the DRT service. Also, on the supply side, decisions of DRT provision may have been based on local area characteristics such as population density and deprivation. This model did not observe a significant difference in DRT use between areas with differing gender or age profiles, though interestingly the coefficient of proportion of white was positive and statistically significant in the IMD model, implying that areas with a higher proportion of white people tend to have a greater demand for DRT. Specifically, using the coefficient estimated from the IMD model, for a 0.01 unit increase in proportion of white (i.e. 1 unit increase in percentage of white) in a LSOA, the corresponding percentage increase in DRT trips was $1.6 \%$, holding all other variables constant. This finding indicates that there may be cultural factors that reduce demand for publicly provided DRT services amongst non-white people.

As for the variable of proportion of people working from home, the coefficient was negative and significant, which suggests that compared to people who go out to work, people who work from home were less likely to use DRT. This is perhaps not unexpected, given that $29 \%$ of all DRT trips in the sample were for employment purposes. In addition, it is expected that some people who are mobility impaired would choose to work from home, which would eventually result in fewer trips (including DRT trips) in an area. Here, for a 1 unit increase in the percentage of people working from home in a LSOA, the corresponding percentage decrease in DRT trips was $13.4 \%$ according to the IMD model, holding all other variables constant.

Finally, DRT operation hours per week and the proxy variables for public transport accessibility such as the proportion of people going to work by public transport were all found to be statistically insignificant in both models.

Table 5 shows five models using different combinations of deprivation domains. These were generally consistent with each other and with the results in Table 4 in terms of the set of statistically significant variables and the signs of their coefficients. There are however a few exceptions. For example, as highlighted in from the models in Table 5 population density is only statistically significant in Model 2; while proportion of white is only significant in Model 5. Proportion of people going to work by public transport becomes significant at $95 \%$ confidence level in Model 1 which is also the model with poorest goodness-of-fit. This suggests that the ID scores used in Model 1 (crime and housing and services scores) failed to account for some of the effects that were previously captured by car ownership or IMD as presented in Table 4. Other proxy variables for public transport accessibility are statistically insignificant in all five models.

Looking at the various ID scores individually, Table 5 shows that, except the crime score, all ID scores were positive and statistically significant. For instance, if an area was highly deprived in terms of income, there would be more DRT trips from the area. A household is less likely to own a private car if it has low income. The employment deprivation domain measures employment deprivation conceptualised as involuntary exclusion of the working-age population from the world of work. Higher employment deprivation may lead to lower income and less likelihood of owning a car, and thus results 
in more DRT trips. The health deprivation and disability domain identifies areas with relatively high rates of people who die prematurely or whose quality of life is impaired by poor health or who are disabled across the whole population. It is expected that people who experience health deprivation or disability would also suffer from mobility problems, which may reduce their resources or ability to use non-DRT modes of transport. As such this group of people may make more DRT trips.

Similarly for the education domain, low levels of educational achievement are often associated with lower incomes and with reduced chances of being employed. As such, areas with a higher level of education deprivation would make more DRT trips. The housing and services domain comprises two aspects. Firstly, 'geographical barriers' (e.g. road distance to a surgery, supermarket or primary school) could mean that people who live in a remote area with a low population density which has already been controlled for in our model. Secondly, 'wider barriers' (which includes issues relating to access to housing such as affordability) still indicate that such groups of people have limited or low income. The crime domain, which measures the rate of recorded crime in Manchester was found to be statistically insignificant. Finally for the living environment domain, the 'indoors' indicator (e.g. houses in poor condition and/or without central heating) suggests that households with such issues are likely to be from a low-income group of the population. In addition, 'outdoor living' environmental issues such as road traffic accidents involving injury to pedestrians and cyclists may lead to an increased number of trips by public transport including DRT, as they are generally perceived to be safer than other modes of road transport (Elvik and Bjørnskau 2005).

The above results confirmed the findings from Table 4 that an area with a higher level of overall deprivation tends to have greater demand for DRT. This result clearly indicates the importance of DRT for highly deprived areas. Overall, Table 5 shows that Model 2, which included the 'education' and 'living environment' scores, provided the best goodness-of-fit in terms of predicting DRT demand from the alternatives analysed.

\section{Discussion}

This paper explored the impact of various factors that influence the use of DRT in Greater Manchester. Looking in more detail at how these findings compare with the literature, in terms of the supply side the results suggest that factors at the service area level account for $20 \%$ of DRT demand, which is an interesting finding in itself and is supported in principle by the structure of Lerman et al. (1980)'s model for predicting DRT demand.

On the demand side (and at the lower LSOA level) meanwhile, a higher amount of DRT trips were generated from areas with a lower population density; a lower proportion of people working from home; a higher proportion of white people; and higher levels of deprivation (as with Nguyen-Hoang and Yeung 2010; Mageean and Nelson 2003). As for population density, the results presented in this paper are also consistent with the literature which suggests that the DRT demand is high in "low-density suburbs" or "limited hard to serve areas" (Nutley 1988; Koffman 2004). As this study was undertaken in mainly urban settings, one may speculate that there would be an even higher demand for DRT in rural areas where population densities are usually lower than in urban areas. If this is the case then it would make sense to invest greater efforts in promoting DRT services in rural areas. However, it should be noted that deprivation levels may be lower in rural areas, so the effects on DRT demand can be complex. Clearly further research needs to be undertaken on DRT services in rural areas. 
Car ownership, as expected, is found to be inversely associated with the number of DRT trips. The results also show that there was a consistent, positive and significant association between the level of deprivation and DRT demand. This suggests that people who are more deprived are more likely to use DRT, which may be due to limited access to private cars. Indeed, as the correlation coefficient between IMD and household car ownership is -0.914 , deprivation is effectively a proxy for car ownership, and vice versa. This result seems to be inconsistent with Nguyen-Hoang and Yeung (2010) as they found a negative association between per cent of poor households and unlinked paratransit trips. However, it should be noted that in their study the variable was only marginally significant (at $90 \%$ confidence level). Moreover our finding confirmed other previous studies which suggested that DRT is primarily being used by groups of users who are "poor" or disadvantaged (SG Associates Inc. et al. 1995; Laws et al. 2009).

Table 4 shows that white ethnic groups use more DRT than non-white, even when the level of deprivation has been controlled for by IMD. This may be due to the differences between cultures, and in attitudes towards public and private transport between white and non-white. It is also noticeable from Table 5 that in Models 1-4 the variable for white was statistically insignificant when different ID scores were used instead of an overall IMD score. Thus it is likely that some effects that were previously controlled for by the variable of white were captured by other ID scores, such as those for employment and education. From this, it is likely that the level or type of deprivation among the white population segment is not homogenous, which may result in the "ecological fallacy" problem (Openshaw 1984). Similarly, the effects of other variables such as the ID scores may also suffer from this problem.

An individual level study may therefore be required to investigate whether a person's individual characteristics (e.g. ethnicity) affect their DRT usage. Area-wide and individual level analyses together would give a thorough view on the effects of factors on DRT trip demand. An individual level analysis however requires highly detailed individual level data, which was unfortunately not available for this study, largely due to disclosure issues. Consequently there was very limited information on passenger level data as evidenced in this study where the only useful data was "client" 6 level gender data (whereby it is known that $77 \%$ of "clients" of DRT in Greater Manchester were female for example). This seems to suggest that women are more likely to use DRT (as supported by the literature e.g. Bearse et al. 2004; Mageean and Nelson 2003; Nelson and Phonphitakchai 2012; Rosenbloom and Fielding 1998), although this effect was not observed from the area-wide level model as shown above. Likewise, the proportion of people aged over 65 was insignificant in the area model, yet numerous individual level studies provide a contrary message (e.g. Fitzgerald et al. 2000; Nguyen-Hoang and Yeung 2010; Mageean and Nelson 2003; Nelson and Phonphitakchai 2012; Rosenbloom and Fielding 1998; Laws 2009). Clearly then, more data is required on passengers and as such other effects on DRT demand could be controlled for such as income, age, distance travelled and fare paid.

\section{Conclusions}

This paper presented the results of a quantitative analysis of DRT provision in Greater Manchester to investigate the effects of various socio-economic factors on the demand for

\footnotetext{
${ }^{6}$ It is worth mentioning that a "client" is the person who booked a DRT trip and the client can book trips for any one and for multiple persons, although $93 \%$ of trips booked were for a single passenger. Some clients also tend to make many more DRT trips than others.
} 
such services. Data for Greater Manchester was collected and a series of multilevel models were employed to examine these factors on DRT demand. This paper is useful for policy makers and practitioners in identifying areas with potential for DRT services, in terms of both the results (i.e. what area characteristics affect DRT demand) and the development of modelling tools.

The multilevel model has successfully taken into account the hierarchical nature of the data. From the modelling results, it was found that factors at the service area level account for around $20 \%$ of DRT demand. At the LSOA level a higher amount of DRT trips were generated from areas with a lower population density; lower proportion of people working from home; a higher proportion of white people; lower car ownership; and higher levels of deprivation (measured by English Indices of Deprivation). Age and gender however were found to be statistically insignificant. Therefore, it appears that close attention needs to be paid to the DRT offering provided (for example in terms of vehicle fleet sizes per operating area and fare levels), and that DRT seemingly has the most potential in areas with a low population density, a low proportion of people working from home, low car ownership, and high levels of deprivation. It is thus speculated that there would be even higher demand for DRT services in rural areas where population densities are usually lower than in urban areas.

For future research, since the data used in is paper is in an urban context, it is yet to develop a model in rural areas. Moreover, an individual level study is required to gain an insight into how individual level factors (e.g. income, age) affect DRT demand, whilst further information about the relative impact of specific service area factors, and fare levels would be particularly beneficial.

Acknowledgments Thanks are due to Transport for Greater Manchester for providing the data for this study and the Engineering and Physical Science Research Council (EPSRC) for their funding of the project Developing Relevant Tools for Demand Responsive Transport (see www.drtfordrt.org.uk; EPSRC Grant reference number: EP/I005455/1). Please contact the corresponding author if you have any queries relating to accessing the data used for conducting this study.

Open Access This article is distributed under the terms of the Creative Commons Attribution License which permits any use, distribution, and reproduction in any medium, provided the original author(s) and the source are credited.

\section{References}

Balcombe, R., Mackett, R., Paulley, N., Preston, J., Shires, J., Titheridge, H., Wardman M., White P.: The Demand for Public Transport, TRL Report 593, Transport Research Laboratory, Crowthorne, Berkshire (2004)

Bearse, P., Gurmu, S., Rapaport, C., Stern, S.: Paratransit demand of disabled people. Transp. Res. B 38(9), 809-831 (2004)

Brake, J., Nelson, J.D., Wright, S.: Demand Responsive Transport: towards the emergence of a new market segment. J. Transp. Geogr. 12(4), 323-327 (2004)

Cervero, R.: Paratransit in America. Praeger, Westport (1997)

Davison, L.J., Enoch, M.P., Ryley, T.J., Quddus, M.A., Wang, C.: Survey of Demand-Responsive Transport in Great Britain. Presented to the 91st Annual Meeting of the Transportation Research Board, Paper 12-3180, Session 477, Rethinking Paratransit, Committee on Paratransit, Transportation Research Board, National Academy of Science, 22-26 January, Washington, DC (2012a)

Davison, L.J., Enoch, M.P., Ryley, T.J., Quddus, M.A., Wang, C.: Market niches for DRT. Res. Transp. Business Manag. 3, 50-61 (2012b)

Department for Communities and Local Government: The English Indices of Deprivation 2007. Department for Communities and Local Government, London (2008) 
Elvik, R., Bjørnskau, T.: How accurately does the public perceive differences in transport risks? An exploratory analysis of scales representing perceived risk. Accid. Anal. Prev. 37(6), 1005-1011 (2005)

Enoch, M.P., Potter, S., Parkhurst, G., Smith, M.T.: INTERMODE: Innovations in Demand Responsive Transport. Department for Transport and Greater Manchester Passenger Transport Executive, London (2004)

Enoch M.P., Ison S.G., Laws R., Zhang L.: Evaluation Study of Demand Responsive Transport Services in Wiltshire, Final Report, Wiltshire County Council, Trowbridge, Wiltshire, July (2006)

Finn, B., Ferrari, A., Sassoli, P.: Goals, requirements and needs of users. In: Abrosini, G., Nelson, J.D., Romanazzo, M. (eds.) Demand Responsive Transport Services: Towards the Flexible Mobility Agency, pp. 33-54. ENEA, Italy (2004)

Fitzgerald, J., Shaunesey, D., Stern, S.: The effect of education programs on paratransit demand of people with disabilities. Transp. Res. A 34(4), 261-285 (2000)

Greater Manchester Combined Authorities and Transport for Greater Manchester. Greater Manchester's third Local Transport Plan 2011/12-2015/16. http://www.tfgm.com/ltp3/documents/Greater_ Manchester_Local_Transport_Plan_Core_Strategy.pdf (2011)

Heck, R.H., Thomas, S.L.: An Introduction to Multilevel Modelling Techniques, 2nd edn. Routledge, London (2009)

Hine, J.: Transport disadvantage and social exclusion in urban Scotland. Built Environ. 30(2), 161-171 (2004)

Khattak, A.J., Yim, Y.: Traveller response to innovative personalized demand-responsive transit in the San Francisco Bay area. J. Urban Plan. Dev. 130(1), 42-55 (2004)

Koffman, D.: Operational Experiences with Flexible Transit Services. Synthesis Report 53, TCRP, Federal Transit Administration, Washington, DC (2004)

Lacometti, A., Setti, L., Scholliers, J., Gorini, M., Eloranta, P.: Technologies for DRT systems. In: Abrosino, G., Nelson, J.D., Romanazzo, M. (eds.) Demand Responsive Transport Services: Towards the Flexible Mobility Agency, pp. 89-109. ENEA, Italy (2004)

Laird, N.M., Ware, J.H.: Random-effects models for longitudinal data. Biometrics 38(4), 963-974 (1982)

Laws R.: Evaluating Publicly Funded DRT Schemes in England and Wales. Ph.D. Thesis, Loughborough University, Loughborough (2009)

Laws, R., Enoch, M.P., Ison, S.G., Potter, S.: Demand responsive transport: a review of schemes in England and Wales. J. Public Transp. 12(1), 19-37 (2009)

Lerman, S.R., Flusberg, M., Pecknold, W.M., Nestle, R.E., Wilson, N.H.M.: A model system for forecasting patronage on demand responsive systems. Transp. Res. A 14A, 13-23 (1980)

Li, X., Quadrifoglio, L.: Feeder transit services: choosing between fixed and demand responsive policy. Transp. Res. C 18, 770-780 (2010)

Long, J.S., Freese, J.: Regression Models for Categorical Dependent Variables Using Stata, 2nd edn. Stata Press, College Station (2006)

Mageean, J., Nelson, J.D.: The evaluation of demand responsive transport services in Europe. J. Transp. Geogr. 11(4), 255-270 (2003)

Nelson, J.D., Phonphitakchai, T.: An evaluation of the user characteristics of an open access DRT service. Res. Transp. Econ. 34(1), 54-65 (2012)

Nguyen-Hoang, P., Yeung, R.: What is paratransit worth? Transp. Res. A 44(10), 841-853 (2010)

Nutley, S.D.: Unconventional modes of transport in the United Kingdom: a review of types and the policy context. Transp. Res. A 22(5), 329-344 (1988)

Office for National Statistics: Key Statistics: Rural and Urban Area Classification Usual Resident Population, 2004 KS01, 2001 Census, ONS, London (2004)

Office for National Statistics: Mid 2011 Components of Change Population Estimates by Local Authority, 2011 Census, ONS, London (2013)

Openshaw, S.: The Modifiable Areal Unit Problem. Concepts and Techniques in Modern Geography, vol. 38. Geo Books, Norwich (1984)

Rosenbloom, S., Fielding, G.J.: Transit Markets of the Future: The Challenge of Change, Report 28, TCRP, Federal Transit Administration, Washington DC (1998)

SG Associates Inc., Leigh, Scott and Cleary Inc., CM Research Inc.: Workbook for Estimating Demand for Rural Passenger Transportation, Report 3, TCRP, Federal Transit Administration, Washington, DC (1995)

Spielberg, F., Pratt, R.H.: Demand Responsive/ADA Traveller Response to Transportation System Changes, Chap. 6, Report 95, TCRP, Federal Transit Administration, Washington, DC (2004).

Tobler, W.R.: A computer movie simulating urban growth in the Detroit region. Econ. Geogr. 46, 234-240 (1970) 


\section{Author Biographies}

Chao Wang is a Research Statistician at the University of Oxford. He received a BEng degree in Transportation Management (Dalian Maritime University) in 2005; an MSc in Transport (Imperial College London) in 2006; and a PhD (Loughborough University) in 2010. His primary research interests include transport modelling and 'big data'.

Mohammed Quddus is a Professor of Intelligent Transport Systems (ITS) at Loughborough University. His primary research interests include transport systems modelling, sensor fusion using artificial intelligence and analysing large transport datasets. He currently serves as an Associate Editor of Transportation Research Part C and Journal of ITS.

Marcus Enoch joined Loughborough University in 2003 and was promoted to be a Senior Lecturer in 2007. He obtained a BEng degree in Civil Engineering (University of Nottingham) in 1993; an MSc degree in Transport Planning and Engineering (University of Leeds) in 1994; and a PhD (Open University) in 1998.

Tim Ryley is a Senior Lecturer in Transport Studies within the School of Civil and Building Engineering at Loughborough University. Ryley has expertise in the following areas: demand responsive transport, walking and cycling, air travel demand, airport surface access, transport and climate change, and travel behaviour analysis.

Lisa Davison is a Lecturer in Transport Studies at the University of Ulster. Her research seeks to contribute to a more sustainable transport system through the study of the behavioural responses of consumers to changes in market and policy conditions. 